\title{
The "Shavadun" as an ecological solution for architecture in a hot climate
}

\author{
R. Rezaee, R. Vakilinejad \& M. Shahzadeh \\ Department of Architecture, Iran University of Science and Technology, \\ Iran
}

\begin{abstract}
Our cities worldwide are plagued with the hazards of global warming, ozone layer destruction and acid rain, caused by the over-consumption of energy. Such dilemmas can be offset by using less energy in innovative ways. We, as architects, have to make important decisions about the types of our buildings. To reach this purpose, ecological design focuses on the human-nature interface and uses nature. Although the green building movement is a relatively recent phenomenon, it has its roots in several previous generations of architecture. In the Iranian context, several figures laid the foundation for today's ecological design. In such traditional buildings many forms, elements, materials, and techniques were used to achieve comfort and respond to the local climate. Courtyards, wind catchers, and shading devices are some of the most successful aspects. However, many probably haven't heard about "Shavadun". It refers to a place situated about seven meters under the ground. In the hot and dry climate of some parts of Iran, "Shavadun" is the best solution, providing comfort for the occupants. In this paper, first we introduce this architectural space according to some case studies in that context. Then we consider some other characteristics of "Shavadun", such as dimensions, temperature, ventilation, and daylight. We focus on the benefits of "Shavadun" as a place for escaping from the hot summer days. Finally we propose ecological solutions based on the principals employed in designing "Shavadun", which can be integrated into today's buildings. The aim of this challenge is to use the wisdom of the past to meet the requirements of the current building, while retaining the positive cultural and environmental aspects of vernacular design.
\end{abstract}

Keywords: Shavadun, underground space, architecture of ecology. 


\section{Introduction}

The environmental impacts of extracting and consuming non-renewable energy resources, such as fossil fuels and nuclear energy, are profound. Pronounced land impacts from coal and uranium mining, acid rain, nitrous oxides, particulates, radiation, ash disposal problems, and the long-term storage of nuclear wastes are just some of the consequences of energy consumption by the built environment [1].

Due to this problem we have to rethink the human-nature interface and using nature; and in the context of the built environment, we have to seek solutions that integrate human-created structures with nature in a symbiotic manner that is harmless to humans and nonhumans. We have to make some very important decisions with respect to how we live and the types of buildings we create. Therefore, creating a low energy profile is a major challenge for designers.

The green building movement and allied efforts are attempting to improve building energy performance. In this aspect, a building must be understood as a complex configuration - a total energy concept - that makes the best possible use of locally available natural resources, such as solar energy, wind and geothermal energy for a variety of requirements [1, 2]. There are so many examples in some ancient countries like Iran, which have been designed in line with the green movement.

\section{Passive design in Iran}

Traditional Iranian buildings offer great examples of what we are trying to achieve in our buildings for the new century and the future. Their underlying principle is amity with the environment. They are close to nature and tailored to local conditions in such a way that provides comfort with minimal energy consumption [3]. Indigenous buildings in Iran successfully minimize the environmental load, and are filled with elegant techniques for making use of natural energy. Such architecture avoids artificial uniformity, creating instead, attractive and heterogeneous interior spaces and harmonious spatial relationships. For example, in the southwest part of Iran, with a hot and semihumid climate, different innovative solutions have been worked out to achieve human comfort. In the residential architecture of this area, in cities like Dezful and Shooshtar, with ancient civilizations, passive strategies and local systems have been used. In these cities underground architecture, as one of the climate design solutions that provides for human needs against an undesirable environment, can be seen. The underground space named "Shavadun" is one of the best solutions providing comfort for the residents of this region.

\section{About the region}

Shooshtar is 831 kilometers from Tehran and enjoys a warm climate in the spring, summer and autumn and cold weather in the winter. Located at $48^{\circ}-20^{\prime}$ 
east latitude and $32^{\circ}-30^{\prime}$ north altitude, Shooshtar is connected to the Khuzestan Plain, through which it reaches the Persian Gulf, while from the other side it is surrounded by mountains. This city has two natural characteristics: the first is its altitude (150 meters) and second is its situation as a bank of the Karoon River. In fact, Shooshtar is located between two branches of the Karoon River [4].

The climate of the city is subject to two seasons of a hot and humid summer and a long spring. From November to the middle of February, it is rather cold. In May, the temperature starts to rise and the three succeeding months of June, July and August are quite hot and humid. Sandstorms occur occasionally during summer from the desert of Saudi Arabia. In May and August, the maximum temperature sometimes rises to 50 degrees Celsius. The minimum temperature in winter goes down to 1 degree Celsius. The average rainfall throughout the year is only $250 \mathrm{~mm}$ and the average relative humidity is about $42 \%$. One of the undesirable winds is the wind that blows from the west and southwest to the east. The desirable wind comes from the north and northwest blowing in all seasons.

A study about the geology of Shooshtar shows that the soil in Shooshtar has conglomerate characteristics, which is clay for layers of 1.5-2 meters depth and conglomerate for layers of 120 meters depth [4,5].

To consider passive design in this region, we have categorized the information in two major aspects: (1) the use of the building site and its location to reduce the building's energy profile; and (2) the design of the building itself, its orientation, aspect ratio, massing, fenestration, ventilation paths, and other measures.

\subsection{Site conditions}

Humidity and hot weather are the most important environmental factors that are effective on the formation of buildings. In order to resist these, making shadows and two-way-across ventilation is essential [5]. Therefore the city has been designed with a compact context with few narrow openings and narrow sideways (the ratio of wall height to the alley width is larger than one) to provide

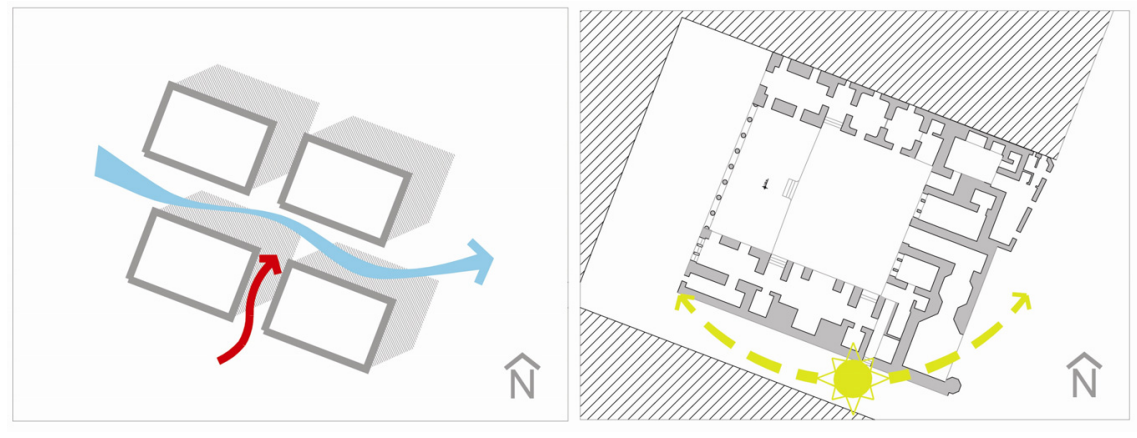

Figure 1: Building orientation according to wind Figure 2: Building orientation direction. according to sun path. 
shadows and withstand the intolerable hot weather. In addition, the wind direction has effected the road orientation toward the river, catching the desirable wind from northwest to southeast.

\subsection{Ecological design}

The type of architecture used in the ancient houses allows people to live in them in different seasons: houses with a large courtyard, high "Ivan", a "Shabestan" and a "Shavadun". In these buildings, the courtyard is an open space in the center of the building that all other spaces are located around. "Ivan" is a semiclosed and ancient element in Iranian architecture that can be seen in these buildings [6]. Elements forming houses can be classified into three types: open spaces, semi-closed and closed spaces. Depending on the environmental conditions and different seasons, one of these three types was selected as a suitable space for living. In fact, the residents were moving, that is, up to 10am in the summer they stayed in the rooms, then at noon they went to the "Shavadun", in the afternoon they go to the "Ivan" and at night they slept on the roof unless the weather was hot; in that case, they might go back to the "Shavadun". This movement during the day is a sign of activity, constant usability and continuous relation between the house spaces. Through this movement in a typical house, we will focus on the "Shavadun", considering the innovative solutions being used in this space. It is obvious that the passive design approach is followed in designing each element including the envelopment, geometry, orientation and mass of a building. These elements have been designed in order to reduce the effect of undesirable environmental conditions to a minimum. However, in this article, our focus will be on the underground spaces, especially the "Shavadun".

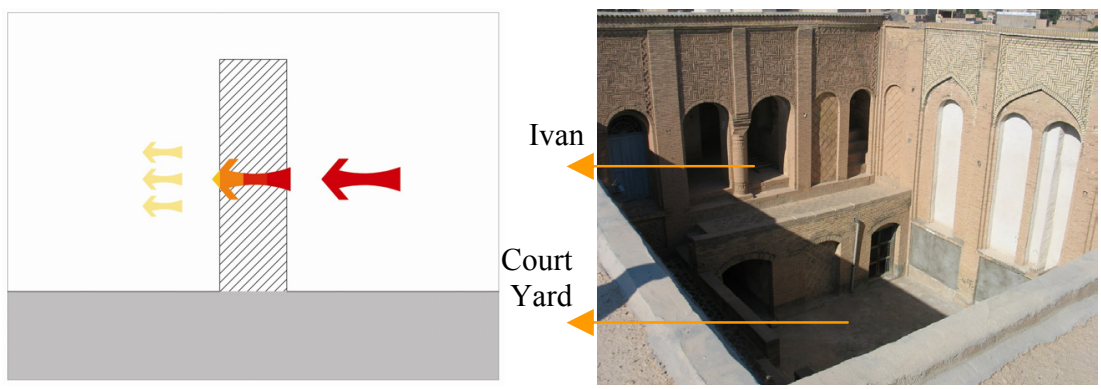

Figure 3: Thermal inertia of the walls/"Ivan" and

Figure 4: Thermal inertia of the walls/'Ivan" and courtyard for cooling purposes. courtyard for cooling purposes. 


\section{4 "Shabestan" and "Shavadun"}

As mentioned above, because of the high temperatures, which sometimes even go up to $45^{\circ} \mathrm{C}$ or higher, and the large amount of humidity, life in some areas becomes difficult and intolerable in the summer.

The "Shabestan" is a space in the basement floor, which is half height and located under the ground level. Lighting and ventilation in the "Shabestan" room are provided through windows located between the courtyard and the "Shabestan" [5]. The "Shabestan" is a part of the building structure that is constructed along with the main building's volume [7].

Although in the hot summer days the "Ivan" space is completely shadowed, it is not useful in the day and since it is not always possible to sleep on the roof during the night, residents go to "Shabestan". However, if they cannot bear the temperature of the "Shabestan", the "Shavadun" is a more comfortable and cooler place $[6,8]$.

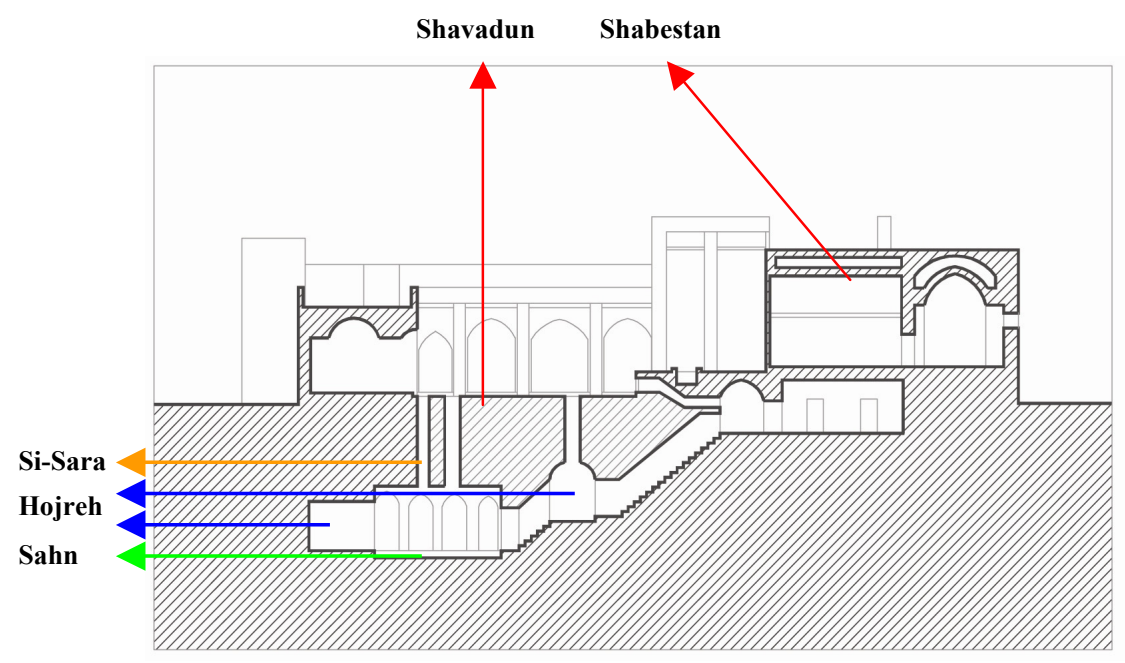

Figure 5: The elements of the "Shavadun" (the section of Moeen Tojjar House).

The "Shavadun" is a cool underground space that is dug deep in the ground, 5 to 12 meters under the courtyard. This space is used for relaxing in the daytime, escaping from hot weather above and also keeping foods. It should be mentioned that the level of underground water in this site is too low and since digging the earth is easy according to the type of soil, there are many "Shavaduns" [5]. In fact, the "Shavadun" is a separate element from the whole building structure, being dug in the depth of the earth with no building material because of its rocky soil. However, in some of the "Shavaduns" there are dome roofs covered with bricks. Notice that these underground spaces are covered with a thick mass of 
soil (about 9 meters high), separating the "Shavadun" from the ground level. The hot weather cannot reach this depth (i.e. this layer acts as an insulating layer preventing the heat transmission between the outdoor environment and this space) and results in cooler temperature.

\subsection{The elements of the "Shavadun"}

The "Shavadun", as shown in Figure 5, consists of Sahn, Hojreh, Sisara and Kooreh.

\subsubsection{Sahn}

The "Shavadun" has a large central space (with a square or polygonal plan), which is accessible from the courtyard or rooms by special stairs. According to the number of "Shavadun" stairs - in some cases up to 50 - there are some landing spaces between a series of stairs, used as rest areas. In these landings there are some retreated areas called "Hojreh".

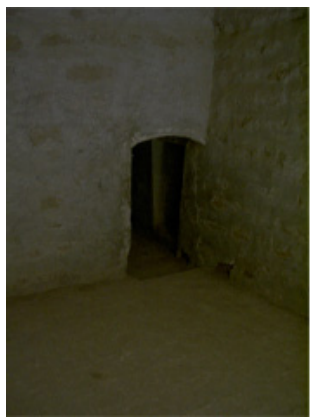

Figure 6:
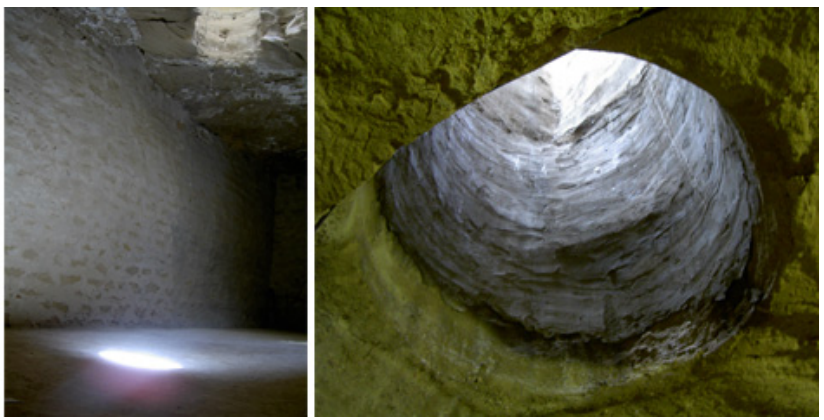

(Left to right) Kooreh, Sahn and Si-sara.

\subsubsection{Hojreh}

The "Hojreh", which is used as a more private space, refers to a room with a retreated area around the Sahn, whose floor is about 30 centimeters higher than the Sahn's floor. It also refers to landings on the stairway, which are about 2 meters wide.

\subsubsection{Si-sara}

The Si-sara is a vertical duct, used mostly for lighting up, which also acts as a fan, directing ventilated weather from the "Shavadun" out to the open space. Different types of Si-sara are connected to the exterior space in various ways: through the courtyard, interior space or an alley. Some "Shavaduns" have been ventilated by means of a wind catcher, which somehow acts as a duct.

\subsubsection{Kooreh}

Horizontal ducts named "Kooreh" are the underground tunnels, up to 1 meter in diameter, used to circulate the air in "Shavaduns" by connecting one's 
"Shavadun" to the neighbors', which provides a family relationship as well. It also creates heat transmission with the exterior space. For instance, in the houses situated next to the river, the "kooreh" is connected to the beach, catching the river breeze for the living space [8].

\section{Studying the temperature of the "Shavadun"}

In order to have exact knowledge of "Shavadun" temperatures, some of these spaces have been selected as case studies, labeled as shown in Table 1. They are coded from A1 to A4. Their temperatures are recorded on the first day of each month in the summer.

\subsection{Comparing the "Shavadun" temperature with the outside in summer}

In Table 2, some sample temperatures, their averages and the open air temperatures are shown. As shown in Table 3, the maximum temperature in the summer is at least $19^{\circ} \mathrm{C}$ above the comfort zone. Besides, the temperature differences are rather great. By comparing Tables 3 and 4, we notice that the temperature of the "Shavadun" is even lower than the minimum temperature of the exterior space. Having a constant temperature is another significant characteristic. Located in the comfort temperature zone, the "Shavadun" needs no cooling device.

Table 1: $\quad$ The case studies.

\begin{tabular}{|c|c|c|}
\hline code & House name & Depth $(\mathrm{m})$ \\
\hline A1 & Marashi & 7,30 \\
\hline A2 & Moeen Tojjar & 11 \\
\hline A3 & Amin Zadeh & 7 \\
\hline A4 & Mostufi & 8,50 \\
\hline
\end{tabular}

Table 2: $\quad$ The temperature of case studies in summer.

\begin{tabular}{|l|c|c|c|c|c|}
\hline Date & A1 & A2 & A3 & A4 & Average \\
\hline 25-Jun & 24,8 & 24 & 24,5 & 24 & 24,3 \\
\hline 25-Jul & 25,3 & 25 & 24,8 & 24,5 & 24,9 \\
\hline 25-Aug & 23,5 & 25,7 & 26 & 25,5 & 25.2 \\
\hline 25-Sep & 26 & 25,7 & 26 & 25,5 & 25,8 \\
\hline
\end{tabular}

\section{2 "Shavadun" temperature in winter}

Winter temperatures of the case studies are shown in Table 4. This Table indicates that the cold winter weather has affected the "Shavadun" and the temperature has slightly decreased. We can use the information in Table 5 to compare the temperature of the "Shavadun" with that of the exterior as indicated 
in this table, while the exterior temperature is $16^{\circ} \mathrm{C}$ below the comfort zone, the "Shavadun" temperature differs by only $3{ }^{\circ} \mathrm{C}$. As a result there is no need to use heating devices because of the almost constant temperate conditions.

Table 3: "Shavadun" sample inside and outside temperatures in summer.

\begin{tabular}{|l|c|c|c|c|}
\hline \multirow{2}{*}{ Date } & The average indoor & \multicolumn{3}{|c|}{ Out-door temperature } \\
\cline { 3 - 5 } & & $\min$ & $\max$ & dif \\
\hline temperature & 24,3 & 25 & 45,5 & 20,5 \\
\hline 25-Jun & 24,9 & 27 & 46 & 19 \\
\hline 25-Aug & 25.2 & 28,5 & 45,5 & 17 \\
\hline 25-Sep & 25,8 & 21 & 40,5 & 19,5 \\
\hline
\end{tabular}

Table 4: $\quad$ The temperature of case studies in winter.

\begin{tabular}{|c|c|c|c|c|c|}
\hline Date & A1 & A2 & A3 & A4 & Average \\
\hline 25-Dec & 18,7 & 18 & 18,5 & 18,5 & 18,4 \\
\hline 25-Jan & 17,3 & 16,8 & 17,5 & 17,5 & 17,2 \\
\hline 25-Feb & 19 & 17,7 & 19 & 18,5 & 18,5 \\
\hline 25-Mar & 20 & 18,5 & 19,5 & 19,5 & 19,3 \\
\hline
\end{tabular}

Table 5: The "Shavadun" inside and outside temperature in winter.

\begin{tabular}{|c|c|c|c|c|}
\hline Date & $\begin{array}{c}\text { The average of } \\
\text { interior } \\
\text { temperature }\end{array}$ & \multicolumn{3}{|c|}{ Outside temperature } \\
\hline 25-Dec & 18,4 & 10,5 & 16 & 5,5 \\
\hline 25-Jan & 17,2 & 5,5 & 12 & 6,5 \\
\hline 25-Feb & 18,5 & 7,5 & 14,5 & 7 \\
\hline 25-Mar & 19,3 & 9 & 14,5 & 5,5 \\
\hline
\end{tabular}

\section{The analysis of the temperature of the "Shavadun"}

In order to find out the cause of the coolness of the "Shavadun" during extremely hot weather, first we present some information about the underground level and its characteristics. Then we will consider air ventilation and its effect on the "Shavadun".

\subsection{Earth and its temperature}

The crust temperature in the lower part of the earth is about $800^{\circ} \mathrm{C}$, which is reduced $3^{\circ} \mathrm{C}$ every 100 meters and the outermost ground layer is colder, almost like the environment temperature. Having connection with objects, the earth's crust can increase or decrease their temperature without any changes in its own temperature. The part of the crust that we build on is the outermost layer, which 
can be affected by the weather temperature. This is divided into two parts based on variation in its temperature. 1. The upper layer on which we construct. This layer gets warmer or colder depending on the seasons and daily heat, as well as its quality (soil, rock). The amount of heat radiation of this layer causes changes in the environment temperature. 2. The lower layer in which we construct the underground floors. This part is 1 to 20 meters deep. Changes as large as $17^{\circ} \mathrm{C}$ in outdoor temperature can change the earth temperature by only $1^{\circ} \mathrm{C}$ at a depth of 1 meter.

Interestingly, a few meters deep in the earth, it takes months to be affected by seasonal changes in environment temperature. As a result, it is possible to save winter coolness and summer warmth for about six months, considering the fact that the earth's temperature at the depth of five or six meters is not affected by tolerances in the weather temperature above.

Since seasonal temperature changes can only affect the temperature of the "Shavadun" by $1^{\circ} \mathrm{C}$ within months, and the average annual temperature of this layer of the earth is $25^{\circ} \mathrm{C}$, as recorded by meteorology statistics, the earth temperature at the depth of the "Shavadun" is in the human comfort zone. As a result this layer can reduce the heat of residents and as little heat enters from hot weather above. So, the earth is the best source of energy, within the layer that does not need to be insulated against heat or cold.

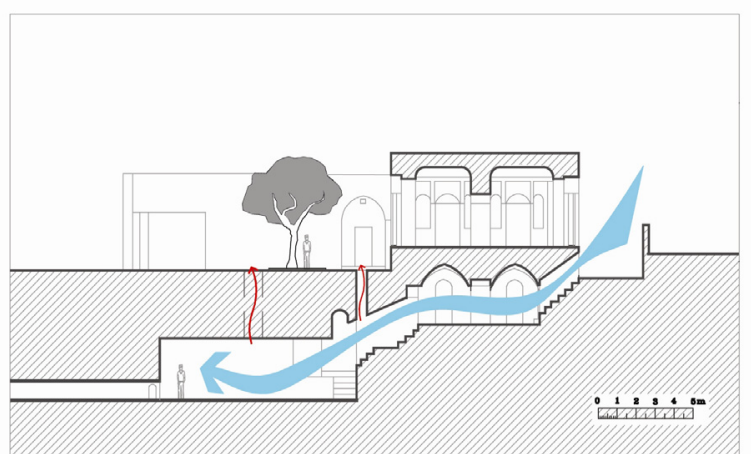

Figure 7: Ventilation in the "Shavadun".

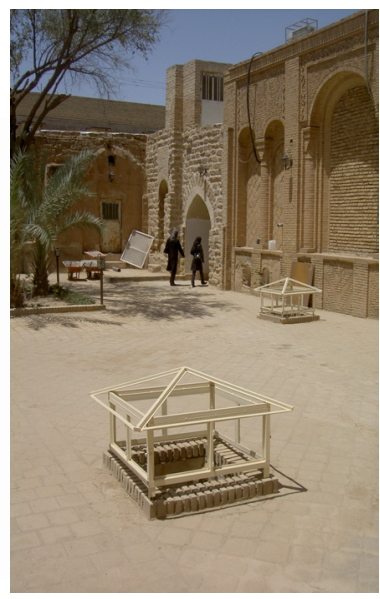

Figure 8: The position of the Si-sara in the courtyard.

\subsection{Weather and its effect on the "Shavadun"}

In addition to the earth's temperature, which cools the "Shavadun" in the summer, ventilation has an important role in cooling through vertical and horizontal ducts. The ventilation system in this underground space is possible 
through the fluid physical property. In the "Shavadun", like other spaces of a house, ventilation is achieved through openings that face the exterior space. Using the chimney effect, the Si-sara exhausts the air out. By exhausting the air through the duct channel, the replacing air enters through the openings or doors in the "Shavadun". Vertical and horizontal ducts with different exterior roads are dug depending on the environmental conditions, house situation and the architect's innovative mind. They present various solutions for air circulation in a "Shavadun".

\section{Ventilation strategy and daylight strategy}

Ventilation is provided using natural forces, greatly reducing the energy needed to move the air. Passive ventilation can be accomplished by using a thermal chimney effect, whereby air normally rises due to heating, inducing air-flow in a generally vertical direction; or a venture effect whereby air movement is induced by the development of a low pressure area created by wind flow (for example wind catchers). Moreover, natural air movement in these buildings feels pleasant.

Using natural light or daylight for illumination is one of the hallmarks of these buildings. In addition to the benefits of supplying substantial light for free, experiencing natural lighting has been shown to provide substantial physical and psychological benefits to the building's occupants. Here, access to daylight is achieved through Si-saras.

\section{Conclusion}

The characteristics of the traditional passive cooling system in Shooshtar, known as the "Shavadun", make it one of the masterpieces of Persian architecture, which can be applied to modern designs. Design thinking should be informed by the traditional efficient methods and techniques employed by older or vernacular buildings, where forms, building, materials, and means of achieving comfort respond to the local climate and hostile surface environment. By taking advantages of these ancient design concepts, designers should temper their selections and specifications to minimize dependency on mechanical and architectural technologies that are difficult to manage and maintain. We aim to learn the lessons offered by these superbly functional traditional buildings and apply them to our own green designs. Imagine a city in which most of its spaces are located underground with large vertical tunnels providing light and fresh air. The microclimate of this underground space remains constant and comfortable, despite the harsh tolerances in outdoor weather temperature. Underground buildings save so much energy in the process of heating or cooling spaces, because the earth is a great heat capacitor. In addition, these buildings have more structural stability. Fire resistance is another benefit. Finally, every square meter of this planet's surface-land and sea is supposed to be robustly alive and saved. Designing underground spaces is a way to achieve this goal. 


\section{References}

[1] Kibert, C.J., Sustainable Construction: Green Building Design and Delivery, Wiley: New Jersey, 2005.

[2] Yeang, K., Ecodesign: A Manual for Ecological Design, Wiley Academy: Great Britain, 2006.

[3] Ray Jones, A., Sustainable Architecture in Japan, Wiley Academy: Great

[4] Robubi, M. \& Rahimiye, F., considering vernacular architecture in hot and semi-humid climate condition, the Union of Tehran University Student: Tehran, pp. 18, 1975.

[5] Ghobadian, V., Climate Analysis of the Traditional Iranian Buildings, University of Tehran Publications: Tehran, 2003

[6] Mashhoodi, S., Historical Analysis of Houses in Shooshtar, The Articles Collection of the History of Iranian Architecture and Urban Design, Iran Cultural Heritage Organization: Kerman, pp. 193, 1996.

[7] Saadat Nia, S., Shushtar, The City Built on Water, The Articles Collection of the History of Iranian Architecture and Urban Design, Iran Cultural Heritage Organization: Kerman, pp. 533, 1996.

[8] Robubi, M. \& Rahimiye, F., "Shavadun \& Shabestan", Asar, 25, Cultural Heritage Organization: Tehran, pp. 200, 1986. 